Thorax (1947). 2. 206.

\title{
RADIOTHERAPY IN CANCER OF THE THORACIC OESOPHAGUS
}

BY

\author{
J. A. C. FLEMING \\ London
}

[For Plates see page 195]

The successful treatment of malignant tumours by radiotherapy is limited by technical and biological factors.

\section{Technical Factors}

Improvements in design and construction of apparatus, greater precision in the measurement of radiation dose not only on the body surface but also at depths below the surface, and the greater penetration of both gamma and $x$ rays achieved by the use of larger quantities of radium and of $x$-ray units operating at higher voltages have all contributed to an ever-increasing efficiency in technique. Although there is room for further improvement, particularly since the recent advent of $x$-ray units operating at several million volts and awaiting full clinical trial, it has been possible for some time to deliver to any tumour a high dose of radiation with reasonable accuracy, irrespective of the position of that tumour in the body.

\section{Biological FACTORS}

In spite of the important technical advances mentioned above, cure of cancer arising in deep-seated thoracic organs has seldom been achieved, because success is prejudiced by certain biological factors. These are chiefly the radiosensitivity and the extent of the tumour.

That different types of tumour vary in their radiosensitivity has been well known for many years, but it is also apparent that a variation exists in the radiosensitivity of malignant growths which arise from similar epithelium ; moreover, the investigations of Glucksmann and Spear (1945) have shown that early disappearance of a squamous epithelioma, as a result of irradiation, may be followed by a recurrence due to the persistence in the irradiated stroma of resistant cells which later multiply. The publications of Glucksmann and Spear referred only to investigations carried out in relation to squamous epithelioma arising in certain accessible sites, but it is reasonable to assume that a similar factor operates in deep-seated cancer.

The extent to which a tumour has spread when the patient is first examined is of great importance to the radiotherapist. Most epithelial tumours are of moderate radiosensitivity and require a heavy dose of radiation if lasting response is to be anticipated. When the cells of a deep-seated epithelial neoplasm have infiltrated into the adjacent tissues to such an extent that the volume of the growth does not exceed 70 to $100 \mathrm{c.cm}$., it is possible to deliver to this block of tissue a dose of radiation of a magnitude which would afford a chance of cure. As the volume of tissure requiring irradiation increases, the constitutional effects upon the patient resulting from such irradiation become increasingly severe, until a point is reached when it is not possible to deliver a lethal dose to the entire volume of tissue 
involved. This is particularly the case in deep-seated tumours when irradiation has to be delivered from external sources through the skin, with consequent injury to a large volume of uninvolved tissue lying superficial to the tumour.

It is assumed that involvement of mediastinal glands in the case of carcinoma of the cesophagus places a patient beyond cure by radiotherapy, not only because of the extent of the tissues which must be involved, but because secondary deposits in glands tend to be radio-resistant.

Another important factor is the belief held by Koller and Smithers (1946) and others that reaction on the part of the normal stroma plays a role in the destruction of tumour cells, so that the larger the tumour the more resistant it becomes to the effects of radiation.

\section{Malignancy and Spread of Carcinoma of the Oesophagus}

The majority of malignant neoplasms arising in the oesophagus are squamous epithelioma. Geschickter (1935) gives the figures of 87 per cent squamous epithelioma to 13 per cent adenocarcinoma, while Farrell (1938), in an investigation of 100 cases, found 78 per cent were squamous epithelioma and 18 per cent adenocarcinoma, 4 per cent being classified as undifferentiated carcinoma. Clayton (1928), amongst 41 cases of oesophageal cancer which he investigated, reports a case of basal-celled carcinoma involving the middle third.

As a rule cancer of the oesophagus is a tumour of moderate radiosensitivity, but it requires a heavy dose in order to produce a response, and cure by radiation can only be expected when the lesion is localized to the gullet.

The thoracic oesophagus lies deeply in the thorax, and a malignant lesion seldom makes itself apparent until interference with the function of the viscus takes place, or until direct or metastatic extension of the tumour to other structures has occurred. Account has then to be taken of the interval of time which elapses from the onset of symptoms until the patient commences treatment.

Unlike malignant disease arising in superficial structures, such as the breast, the extent of the disease in carcinoma of the oesophagus is not so easy to determine when the patient presents himself for treatment, and it is chiefly by a study of post-mortem material in relation to survival that we can gain information on this point. McGibbon (1936) states that cancer of the oesophagus is highly malignant and stresses the latent period of 5 or 6 months which generally elapses between the onset of the disease and the appearance of symptoms; a similar period exists from the onset of symptoms until the condition has been diagnosed, making a total of 10 to 12 months from the start of the lesion until diagnosis; the average duration of life after diagnosis is 5 months. This author investigated one hundred cases, and ten out of thirteen which came to autopsy had extensive involvement of lymph glands in thorax and abdomen. Clayton (1928) in an investigation of 41 cases of carcinoma found that an average interval of about 7 months existed from the onset of symptoms until death. Dormanns (1939), in an investigation of over fourteen hundred cases of cancer of the oesophagus collected from 39 pathological institutes in Germany, found the average length of time from 
the first subjective symptoms until death amounted to 7.3 months, and the average duration of survival from first examination amounted to about 10 weeks. Fleming had made a similar investigation in 40 patients who had not received any treatment apart from gastrostomy or intubation; 34 of these were described in a previous publication (1943), an additional 6 having been investigated recently. In this group the average length of symptoms, before examination, amounted to 3.9 months, while the average duration of survival from first examination amounted to 5.2 months. The average survival after diagnosis was 6 weeks.

Thus in three of the four investigations quoted, namely Clayton (1928), Dormanns (1939), and the author, a comparatively short interval elapsed from diagnosis until death in cases confirmed by autopsy, and, even allowing for some increase in the spread of the disease during this interval, the final state at autopsy gave some indication as to the extent of the disease when diagnosis was first made.

Clayton (1928) showed that of 41 cases of carcinoma of the oesophagus 75 per cent showed metastatic spread. This figure is corroborated by the much larger series of 1,439 cases investigated by Dormanns, who found that only 309, or 21.5 per cent, showed no spread beyond the oesophagus at autopsy.

Cade (1940) also stresses the high malignancy of this condition, and, from the published observations of several authors, states that over 50 per cent of cases show metastases at autopsy. He considers that the average duration of survival from onset of symptoms amounts to between 8 and 10 months, and he draws attention to the liability for cancer to spread in the submucous lymphatics which may manifest itself as seedling outcrops of tumour some distance from the visible primary (Plate XV).

The author has investigated post-mortem records of 52 patients with oesophageal cancer who had not received radiotherapy or radical surgery; 10 of these were investigated recently and added to 42 already published (Fleming, 1943). At autopsy 41, or 79 per cent, of these showed spread beyond the oesophagus, including distant metastases. In his previous communication Fleming showed that there appeared to be some relationship between the length of gullet involved by visible carcinoma and the degree of spread beyond the viscus. An arbitrary grading of tumburs was made, in relation to their spread, in order to separate those which could theoretically be included in a zone of high dosage of irradiation in and around the oesophagus from those in which it was probable that the careinoma had extended to regions outside this zone.

The tumours were graded as follows. Stage I: the growth was macroscopically entirely confined to the oesophagus. Stage II: the growth had involved adjacent structures by direct spread, but not extensively. Stage III: the mediastinal lymph nodes were involved. Stage IV: there were distant metastases. Of the 45 cases investigated, 34, or 75.6 per cent, were in stages III and IV, while 11, or 24.4 per cent, were in stages I and II. 
The tables indicate the degree of spread in accordance with this arbitrary grading, and in relation to the length of the lesion as found at autopsy. Relevant data was found in 76 of the cases published and investigated by Fleming and Clayton.

TABLE I

FLEMING

(40 cases, including 35 cases* previously published)

\begin{tabular}{cc|c|c|c|c|c|c}
\hline $\begin{array}{c}\text { Length } \\
\text { of growth }\end{array}$ & $\begin{array}{c}\text { Total } \\
\text { No. }\end{array}$ & Stage I & Stage II & Stage III & Stage IV & $\begin{array}{c}\text { Per cent } \\
\text { I and II }\end{array}$ \\
\hline $\begin{array}{llll}\text { Up to } 5.1 \mathrm{~cm} . \\
\text { Above } 5.1 \mathrm{~cm} .\end{array}$ &. & 18 & 9 & 1 & 3 & 5 & $55.7 \%$ \\
\hline
\end{tabular}

* This figure was given in error as 34 in Table III of the author's previous article (Fleming, 1943), and has here been corrected.

TABIE II

CLAYTON

(36 cases, as previously published)

\begin{tabular}{cc|c|c|c|c|c|c}
\hline $\begin{array}{c}\text { Length } \\
\text { of growth }\end{array}$ & $\begin{array}{c}\text { Total } \\
\text { No. }\end{array}$ & Stage I & Stage II & Stage III & Stage IV & $\begin{array}{c}\text { Per cent } \\
\text { I and II }\end{array}$ \\
\hline $\begin{array}{c}\text { Up to } 5.1 \mathrm{~cm} . \\
\text { Above } 5.1 \mathrm{~cm} .\end{array}$ & $\ldots$ & 16 & 5 & 2 & 2 & 7 & $43.7 \%$ \\
\hline
\end{tabular}

TABLE III

COMBINED TABLES I AND II (76 cases)

\begin{tabular}{cc|c|c|c|c|c|c}
\hline $\begin{array}{c}\text { Length } \\
\text { of growth }\end{array}$ & $\begin{array}{c}\text { Total } \\
\text { No. }\end{array}$ & Stage I & Stage II & Stage III & Stage IV & $\begin{array}{c}\text { Per cent } \\
\text { I and II }\end{array}$ \\
\hline $\begin{array}{c}\text { Up to } 5.1 \mathrm{~cm} . \\
\text { Above } 5.1 \mathrm{~cm} .\end{array}$ & $\ldots$ & 34 & 14 & 3 & 5 & 12 & $50 \%$ \\
\hline
\end{tabular}

These tables suggest that when the visible lesion exceeds $5.1 \mathrm{~cm}$. in length the possibility that radiotherapy will affect a permanent cure is small. Moreover there is a short survival period from the onset of symptoms in untreated oesophageal cancer, and when this is considered in relation to the widespread nature of the disease, as found at autopsy, the prognosis of most cases, when they present themselves for treatment by radiotherapy, is not hopeful as far as permanent cure is concerned.

Finally, the bad general condition of many patients suffering from this disease when they first present themselves for treatment renders them poor subjects to withstand heavy doses of irradiation through large volumes of tissue. 
The Treatment of Carcinoma of the Oesophagus by Radiotherapy

Three different methods have been used.

\section{The insertion of radon seeds}

Insertion of radon seeds (by any method) suffers from the disadvantage that it is impossible to place the radium so that an adequate and even dose of irradiation is delivered throughout the tumour.

Souttar (1934) has described a technique for insertion or application of radon into or around growths involving the lower end of the oesophagus, after transthoracic exploration. He claimed good palliative results. The introduction of radon seeds into growths at the cardio-oesophageal junction by laparotomy is also in practice as a palliative measure, and similar palliation with return of swallowing can be obtained in cases where radon seeds have been inserted into the growth by endoscopy. In all these methods the range of effective radiation is limited and does not affect all parts of the tumour, especially if it is of any size.

Pohle and Benson (1943) report a 7-year "cure" in one case out of 85 which involved the upper end of the oesophagus and which were treated by insertion of radon seeds followed by three courses of $x$-ray therapy. But the average duration of survival after admission was only 6 or 7 months.

The insertion of radon seeds into the oesophagus by endoscopy carries the risk of mediastinal perforation, and Cleminson and Monkhouse (1934) refer to this in their series of 89 cases. No increase in survival rate was obtained by these authors, but in suitable cases this technique has resulted in good primary relief of symptoms.

\section{Bougie containing radium tubes}

The introduction into the lumen of the oesophagus of a bougie containing radium tubes has the advantage that radiation can be uniformly applied to the surface of the growth without irradiating large volumes of normal tissue. Unfortunately the depth of effective radiation thus achieved is relatively small, and tumours which have spread beyond the immediate vicinity of the mucosal surface are not adequately irradiated. In spite of these limitations this method has met with success in the hands of Guisez, whose results, quoted by Smithers and others (1943), show that, of 270 cases treated, 3 have survived for over 5 years, and 8 between 3 and 4 years. Guisez (1937) also states that one patient is alive 26 years after treatment. Similar results have not been obtained by others using the same method. More recently Lederman and Clarkson (1945) published the results of treatment in 48 cases of tumours involving the upper two-thirds of the oesophagus, by using the radium bougie under conditions of careful physical control ; Lederman and Clarkson recommend radon seeds implanted by laparotomy for tumours of the lower third, and claim good palliative results. By use of the bougie they also obtained excellent palliative results with early return of swallowing in a high 
proportion of cases. In 15 cases where the lesion occurred in the upper third, survival periods varied from 1 to 4 years, but there were no 5-year survivals. In 33 cases where the tumour involved the middle of the oesophagus one case survived for $2 \frac{1}{2}$ years, the remainder died within 6 months.

\section{$X$ rays applied from without}

$X$ rays applied from without have been widely used in the treatment of oesophageal cancer, and in order to obtain a sufficiently high dose of radiation in the tumour without subjecting the skin to a dose beyond its tolerance, $x$-ray units operating in excess of 200 kilovolts are generally employed, together with the use of multiple skin fields cross-firing the tumour zone. Physically, $x$-ray therapy is capable of adequately irradiating the tissues potentially invaded by a tumour only at the expense of irradiating a greater volume of normal tissue, thus producing in some cases profound constitutional effects. In spite of the greater volume of tissue which can be irradiated by high-voltage units, the published results to date of $x$-ray therapy for oesophageal cancer are not encouraging from the point of view of permanent cure, but in a considerable proportion of patients relief of obstruction can be obtained for varying periods of time. Nielson (1940) reports the results of $x$-ray therapy administered to 109 patients during the 7 years from 1931 to 1938, and amongst these 17, or 18.5 per cent, were treated with the object of achieving a cure. In all 17 cases there was marked shrinkage of the tumour, with relief of obstruction. Eight of the 'patients were alive at the end of 1 year. Of these 1 died of recurrence $3 \frac{1}{2}$ years later ; 1 was still alive (with recurrence and metastases) 2 years after treatment ; 4 were alive and free from symptoms ( 2 of these were alive at the end of $3 \frac{1}{2}$ years, 1 at the end of $2 \frac{1}{2}$ years, and the fourth, a case of cancer at the upper end, was alive and well 6 years after treatment); and 2 patients were alive but with recurrence, 1 at the end of 1 year and 1 at the end of 2 years. Hence, of the 109 patients treated, only 1 survived for over 5 years.

Engelstad (1939) reports the results of treatment in 119 patients, in 68 of whom a positive biopsy was obtained. Four were treated by radium alone, and the remainder by $x$ rays alone, or by a combination of $x$ rays and radium. Of these 119 patients, 10 were alive at the time of survey, but the longest survival after treatment was 1 patient who lived 14 months. Of the fatal cases, 35 per cent survived fewer than 6 months after therapy, and the remainder survived for periods varying from 6 months to 2 years. This author stresses the advanced condition of the disease when symptoms first manifest themselves. An analysis of the size of the lesions in these cases when they first came to treatment showed that 109 had a tumour more than $5 \mathrm{~cm}$. long, whereas in only 38 per cent was there clinical evidence of metastases.

Strandqvist (1941) considers that the tumour reaches a considerable size in a few months and that small local mestastases appear early. He treated 36 cases at the Radiumhemmet. Stockholm, by $x$-ray therapy alone; all were 
considered to have passed the early stage when treated. Primary freedom from symptoms was obtained in 75 per cent, and palliation was excellent. Of the 36 cases treated, 18, or 50 per cent, died of cancer or necrosis within 1 year; 5 , or 14 per cent, died of perforation within 3 months, and 9, or 25 per cent, died of other complications within 9 months. In 5 of the 14 cases who died of perforation or other complications, an autopsy was performed and showed no viable cancer in the oesophagus. Of the remaining 4, or 11 per cent, 1 woman lived symptom-free for $2 \frac{1}{2}$ years and died of myocarditis, and no evidence. of cancer was found post-mortem ; 1 woman lived symptom-free for over two years, but the cause of death was unknown ; 1 woman was alive and symptom-free at the end of 3 years; and 1 man was alive and symptom-free at the end of 2 years.

Smithers and others (1943) analyse the results of 51 cases of oesophageal cancer treated by $x$-ray therapy at the Royal Cancer Hospital. This series was treated largely by a unit operating at $\mathbf{4 0 0}$ kilovolts, and was composed of cases first seen between 1937 and 1939. An analysis of the 32 cases which completed treatment showed that 14 , or 44 per cent, lived for 1 year or more after treatment ; 9 , or 28 per cent, died between 6 and 12 months after treatment; and 9, or 28 per cent, died in less than 6 months after treatment. Of the 14 who survived over 1 year, 5 survived for more than 2 years, of whom 3 were still surviving at the time of the report, 2 for more than 5 years and 1 for over 4 years. In 11, or 33 per cent, of this series, the patients were known to have developed distant metastases after treatment, and this figure should probably be higher, as in about 40 per cent of the patients who died no information as to the cause of death was obtained. Smithers stresses the palliative value of $x$-ray therapy.

Buschke and Cantril (1944) publish their results in a small series of 10 cases treated by $x$-ray therapy using a unit operating at 800 kilovolts. Of these 10 cases, only 5 completed treatment. One was still surviving after $3 \frac{1}{2}$ years without evidence of local recurrence; 1 was still surviving after 2 years but with a recurrent stenosis ; 2 died of metastases after a few months; and 1 died after 3 months with perforation of the oesophagus and lung abscess.

Phillips (1944) publishes the results of 31 cases treated by supervoltage $x$-ray therapy, using a unit operating at one million volts. His cases were treated between 1937 and 1941. Four survived over 1 year, and 2 for over 2 years. There were no 3 -year survivals. Hence about 80 per cent died within 1 year. Commenting on these results, Phillips suggests that the immediate cause of death in many cases is not metastases but a poor state of nutrition leading to a terminal bronchopneumonia, and also in some cases to perforation of the aorta, from a failure on the part of the tissues to repair the gap left by the tumour. This is supported by the fact that after treatment no evidence of neoplasm may be found, and as a rule no evidence of radiation necrosis at autopsy. Phillips mentions that treatment is usually followed by a relief of dysphagia, and patients are often able to swallow fluids until death. 
In the second statistical report from the Holt Radium Institute, Manchester (1946), cancer of the oesophagus is included in a "poor prognosis group." Ninety cases in all were treated between 1934 and 1938, 11 by radium bougie or intubation, the remainder by radical or palliative $x$-ray therapy.

No patient receiving either radium bougie or intubation or palliative treatment survived as long as five years; but two receiving radical $x$-ray therapy survived this period, one eventually dying of metastases but with a healed primary lesion, the other of probable late radiation change in lungs.

The author has surveyed the follow-up records of 10 additional cases, in all of whom the follow-up notes were complete, treated by deep $x$-ray therapy at St. Thomas's Hospital since 1943. The voltage of the units used varied from 200 to 250 kilovolts, the lesion being treated through six skin fields after radiographic localization. The duration of symptoms before hospitalization varied from 7 weeks to 7 months, with an average of about 3 months. Of the 6 cases surviving at the time of survey, 1 has lived for 2 years and was well when last seen; 1 has survived for 9 months. without definite evidence of recurrence ; 1 has survived for 9 months but has had local recurrence (these three cases were of squamous carcinoma). One patient in whom no biopsy was performed was dying 9 months after treatment of clinical carcinoma. Two patients in whom no biopsy was performed were dying of carcinoma less than 6 months after treatment. Of the 4 patients who died, the survival periods after treatment varied from $2 \frac{1}{2}$ months to 6 months, and of the 10 patients treated good primary relief of dysphagia was noted in 6, with a lesser amelioration of symptoms in 2.

The cases quoted are too few for statistical analysis, but the results tend to conform with those of other observers, and are similar to those found in an analysis of 21 cases of cancer of the oesophagus treated by deep $x$-ray therapy, and described in a previous publication (Fleming, 1943).

\section{The Place of Radiotherapy in the Treatment of Oesophageal Cancer}

An investigation into the behaviour of cancer involving the thoracic oesophagus where no treatment, apart from palliative gastrostomy or intubation in some, had been carried out, and an analysis of the subsequent autopsy records, demonstrate two factors of importance when treatment by radiation is contemplated, namely that the disease is highly lethal, and that in an important proportion of cases it has spread to regions outside the oesophagus by the time treatment is begun. Thus, even if $\backslash$ the primary tumour responds the mestastases are lethal.

A review of the published figures of 10 authors already quoted indicate that, of some 800 patients treated by various forms of radiotherapy, and where observations had covered a period of over 5 years, only 10 patients survived more than 5 years, and in one at least of these 10 death occurred ultimately from metastases. 
In spite, therefore, of the technical advances which have been made in radiotherapy over the last 10 or 15 years, the cure of oesophageal cancer by this method of treatment is rare. This failure is no doubt due in part to the advanced condition of the disease when the patients first report for treatment. Many succumb early after treatment from malnutrition with terminal bronchopneumonia or other sequelae. Added to this are the constitutional and regional effects of irradiation on the patient, the former causing a further lowering of vitality, including leucopenia, the latter producing effects from high dose on neighbouring vital structures. Levitt (1940) has suggested that death is often due to a mediastinitis caused by heavy external irradiation, and suggests a combination of internal and external irradiation. A certain number of patients also die soon after treatment through perforation causing septic mediastinitis or lung abscess. A small percentage die from haemorrhage caused by perforation of a large blood vessel.

In other cases there may be a local recurrence in the treated area, due either to the application of a dose below that lethal to the tumour, of to the persistence of potentially viable cancer cells as suggested by the observations of Glücksmann and Spear. Also, in cases where extensive submucous permeation of lymphatics wide of the visible tumour may have taken place, or where for technical reasons the entire tumour had not been included in the zone of irradiation, there may be recurrence in the oesophagus outside the treated zone.

A further analysis of the published results of 7 of the authors who give details of survival times.indicates that, of 417 patients treated by various forms of irradiation, about 83 per cent died within a year, and of 212 patients quoted by 3 of the authors, about 58 per cent died within 6 months and 79 per cent within 1 year. The best results of this series are those published by Smithers, who used deep $x$-ray therapy alone. Of 32 patients who completed treatment, 28 per cent died within 6 months and 56 per cent within 1 year ; 44 per cent survived for periods varying from 1 year to over 6 years.

The figures revealed by the published results quoted, as well as the analysis of material investigated by the author, are depressing. Not only is permanent cure by radiotherapy rare, but most patients fail to survive over 12 months. Most observers, however, stress the early relief of dysphagia and obstruction which occurs in a high proportion of cases during and immediately following treatment, a relief which can render the admittedly short period of survival more tolerable. It should be noted that, of the relatively small percentage of treated cases where autopsy records are available, a certain number show no evidence of cancer in the oesophagus itself when treatment has been adequate.

\section{CONCLUSION}

Radiotherapy has failed so far to cure any but a very few cases of oesophageal cancer, nor has any material increase in survival been achieved. The insidious and highly malignant nature of the disease renders it unlikely that 
many lasting cures will be obtained by present methods of radiation therapy. Its chief value lies in the relief of dysphagia afforded to a considerable number of cases. This relief, coupled with the fact that in a small percentage longer survival may be achieved, which may yet be improved upon to some extent by variations in technique and better after-care of patients, does afford to many cases beyond the scope of surgery a method of treatment still worth while, providing its limitations are appreciated.

On the whole better results from radiotherapy appear to have been achieved in the treatment of tumours involving the upper third of the gullet than in those involving the lower two-thirds. This fact may favour a decision to use radiotherapy for an early lesion in the upper third, particularly if surgery is likely to prove difficult.

\section{SUMMARY}

1. Technical factors governing the treatment of oesophageal cancer by radiotherapy are mentioned.

2. The pathology of the disease is discussed with reference to its malignancy and spread, and the influence of these factors upon the prognosis is analysed.

3. Various methods of treatment by radiotherapy, and the results obtained, are discussed.

I should like to express my appreciation and thanks to Prof. W. G. Barnard, Professor of Pathology, St. Thomas's Hospital Medical School, for his kind permission to make use of material in his department for the purpose of this publication.

\section{REFERENCES}

Buschke, F., and Cantril, S. T. (1944). Radiology, 42, 480.

Cade, S. (1940). "Malignant Disease and its Treatment by Radium." Pp. 988-9. 1st edit. John Wright and Sons. Bristol.

Clayton, E. S. (1928). Surg. Gynec. Obstet., 46, 52.

Cleminson, F. J., and Monkhouse, J. P. (1934). J. Laryng., 49, 313.

Dormanns, E. (1939). Z. Krebsforsch., 49, 86.

Engelstau, R. B. (1939). Acta radiol., 20, 469.

Farrell, J. T., Jr. (1938). Radiology, 30, 412.

Fleming, J. A. C. (1943). Brit. J. Radiol., 16, 212.

Geschickter, C. F. (1935). Amer. J. Cancer, 25, 130.

Glücksmann, A., and Spear, F. G. (1945). Brit. J. Radiol., 18, 313.

Guisez, J. (1937). Presse méd., 45, 1135.

Holt Radium Institute, Manchester (1946). "The Results of Radium and $X$-ray Therapy in Malignant Disease." 2nd rep. Pp. 120-2. E. and S. Livingstone. Edinburgh.

Koller, P. C., and Smithers, D. W. (1946). Brit. J. Radiol., 19, 89.

Lederman, M., and Clarkson, J. (1945). Brit. J. Radiol., 18, 22.

Levitt, W. M. (1940). J. Laryng., 55, 251.

McGibbon, J. E. G. (1936). Brit. J. Surg., 24, 86.

Nielson, J. (1940). Acta radiol., 21, 352.

Phillips, R. (1944). "Supervoltage $X$-ray Therapy." Pp. 129-31. H. K. Lewis and Co. London.

Pohle, E., and Benson, R. R. (1943). Amer. J. Roentgen., 50, 89.

Smithers, D. W. (1943). Brit. J. Radiol., 16, 317.

Smithers, D. W., Clarkson, J. R., and Strong, J. A. (1943). Amer. J. Roentgen., 49, 606.

Souttar, H. S. (1934). " Radium and Cancer." Pp. 296-8. Wm. Heinemann. London.

Strandqvist, M. (1941). Acta radiol., 22, 172. 